\title{
Enzymatic Activity of Prototheca zopfii Strains Isolated from Cows with Mastitis
}

\author{
HENRYK KRUKOWSKI*, ANDRZEJ LISOWSKI, BOŻENA NOWAKOWICZ-DĘBEK and ŁUKASZ WLAZŁO \\ Department of Animal and Environmental Hygiene, University of Life Sciences, Lublin, Poland
}

Received 26 October 2011, revised 28 June 2012, accepted 3 July 2012

\begin{abstract}
Bovine mastitis caused by Prototheca spp. can be a disease of high significance because of economic losses and the potential risk to public health. The aim of our study was to evaluate enzymatic activity of Prototheca zopfii. For this study, we used 15 P. zopfii strains previously isolated from cows with clinical and subclinical mastitis in Poland. We determined enzymatic profile of Prototheca species using the API ZYM system. Of the enzymatic activities detected during the study, acid phosphatase, leucine arylamidase, naphthol-as-bi-phosphohydrolase, esterase, lipase esterase, valine arylamidase, alkaline phosphatase, and lipase C14 were found in high percentage of strains.
\end{abstract}

Key words: Prototheca zopfii, mastitis, API ZYM

The genus Prototheca includes unicellular achlorophyllous microalgae that belong to the family Chlorellaceae. These organisms reproduce asexually by formation of variable numbers of sporangiospores within a sporangium (Marques et al., 2010). Prototheca spp. can be found in the environment as ubiquitous detritus inhabitants and contaminants of various substrates (Lass-Flörl and Mayr, 2007). Prototheca spp. are often associated with wet areas containing decaying manure and plant matter. The increasing number of isolations of Prototheca spp. from 5-14\% of bovine mastitis cases indicates the need of a detailed evaluation of this problem (Bueno et al., 2006; Costa et al., 1996). Prototheca mastitis in cows is mostly caused by Prototheca zopfii (Costa et al., 1996; Cunha et al., 2010; Cunha et al., 2006; Jagielski et al., 2010; Jagielski et al., 2011; Lassa et al., 2011; Roesler et al., 2006) and sometimes by Prototheca wickerhamii (Marques et al., 2006) although P. wickerhamii is isolated primarily from humans (Galan et al., 2006; Lass-Flörl and Mayr, 2007).

The enzymatic activity of the yeast, molds and dermatophytes can be a symptom of their virulence, as well as a factor facilitating their invasion (Brasch and Zaldua, 1994; Krajewska-Kułak et al., 1998). For this reason, the aim of the present study was to evaluate enzymatic activity of P. zopfii isolated from the cows with clinical and subclinical mastitis in Poland.

For this study, 15 P.zopfii isolates previously obtained from clinical and subclinical bovine mastitis were subcultured on Sabouraud 4\% dextrose agar
(bioMe'rieux, Poland) and incubated for 48 to $72 \mathrm{~h}$ at $37^{\circ} \mathrm{C}$. Identification was performed using routine culture, macro- and microscopic morphological characterization, and API 20CAUX (bioMe'rieux, Poland) methods (Marques et al., 2006; Padhye et al., 1979; Costa et al., 1996; Costa et al., 1997). We also used test that differentiates of each species of algae based on their susceptibility to clotrimazole according to Casal and Gutierrez (1983). The disks with antibiotic used in this study contained $50 \mu \mathrm{g}$ of clotrimazole, susceptibility was defined as a zone of inhibition of $10 \mathrm{~mm}$ or more. Based upon morphologic features, resistance to clotrimazole and ability to assimilate glucose and glycerol all isolates were identified as P. zopfii.

In this study the enzymatic profile of Prototheca species was determined using the API ZYM system. The API ZYM system (bioMe'rieux, Poland) is a semiquantitative micromethod which allows rapid determination of 19 enzymatic reactions.

Investigated strains were characterized by the activity of enzymes listed in Table I. We detected enzymatic activities of alkaline phosphatase, esterase, esterase lipase, lipase C14, leucine arylamidase, valine arylamidase, acid phosphatase and naphthol-as-biphosphohydrolase. These enzymes were produced by majority of strains, with the exception of lipase C14, where only 5 strains were producing this enzyme.

None of the strains exhibited activity of trypsin, $\alpha$-chymotrypsin, $\alpha$-galactosidase, $\beta$-glucuronidase, $\mathrm{N}$-acetyl- $\beta$-glucosaminidase, $\alpha$-mannosidase, $\alpha$-fucosidase,

\footnotetext{
* Corresponding author: H. Krukowski Department of Animal and Environmental Hygiene, University of Life Sciences, Lublin, Poland; e-mail: henryk.krukowski@up.lublin.pl
} 
Table I

Enzyme activity of 15 strains of Prototheca zopfii in API ZYM test

\begin{tabular}{|r|l|c|c|}
\hline \multicolumn{2}{|c|}{ Enzyme test } & $\begin{array}{c}\text { Number } \\
\text { of strains }\end{array}$ & $\begin{array}{c}\% \\
\text { of strains }\end{array}$ \\
\hline I & check & 0 & 0 \\
\hline II & alkaline phosphatase & 11 & 73,33 \\
\hline III & esterase & 15 & 100 \\
\hline IV & esteraze lipase & 15 & 100 \\
\hline V & lipase C14 & 5 & 33,33 \\
\hline VI & leucine arylamidase & 15 & 100 \\
\hline VII & valine arylamidase & 11 & 73,33 \\
\hline VIII & cystine arylamidase & 0 & 0 \\
\hline IX & trypsin & 0 & 0 \\
\hline X & $\alpha$-chymotrypsine & 0 & 0 \\
\hline XI & acid phosphatase & 15 & 100 \\
\hline XII & naphthol-as-biphosphohydrolase & 15 & 100 \\
\hline XIII & $\alpha$-galactosidase & 0 & 0 \\
\hline XIV & $\beta$-galactosidase & 0 & 0 \\
\hline XV & $\beta$-glucuronidase & 0 & 0 \\
\hline XVI & $\alpha$-glucosidase & 0 & 0 \\
\hline XVII & $\beta$-glucosidase & 0 & 0 \\
\hline XVIII & n-acetyl-b-glucoseaminidase & 0 & 0 \\
\hline XIX & $\alpha$-manosidase & 0 & 0 \\
\hline XX & $\alpha$-fucosidase & 0 & 0 \\
\hline
\end{tabular}

cystine arylamidase, $\beta$-galactosidase, $\alpha$-glucosidase, $\beta$-glucosidase, $\alpha$-fucosidase, and $\mathrm{N}$-acetyl- $\beta$-glucosaminidase.

Enzymatic activity of P. zopfii isolates was in close similarity to those stated by Malinowski et al. (2002) and Casal et al. (1985).

P. zopfii is one of the most responsible for bovine prototheca mastitis. The agent is widely disseminated in the environment and its occurrence in herds is generally associated with the presence of mud, use of contaminated water during milking and flaws in milking routines (Bueno et al., 2006). Milk from cows with prototheca mastitis usually has elevated somatic cell counts to the point that it can be elevated in bulk tank milk, as well as the standard plate count for the herd may also be elevated. Due to the detrimental impact of prototheca infections on milk quality and lack of response to treatment, culling is advised for known infected cows (Kirk and Mellenberge, http://www.uwex.edu/milkquality/ $\mathrm{PDF} /$ prototheca.pdf).

\section{Literature}

Brasch J. and M. Zaldua. 1994: Enzyme patterns of dermatophytes. Mycoses. 37: 11-16.

Bueno V.F.F., A.J. de Mesquita, R.B.S. Neves, M.A. de Souza, A.R. Ribeiro, E.S. Nicolau and A.N. de Oliveira. 2006. Epidemio- logical and clinical aspects of the first outbreak of bovine mastitis caused by Prototheca zopfii in Goia's State, Brazil. Mycopathologia, 161: 141-145.

Casal M.J. and J. Gutierrez. 1983. Simple new test for rapid differentiation of Prototheca wickerhamii from Prototheca zopfi. J. Clin. Microbiol. 18: 992-993.

Casal M., M.J. Linares and M.M. Morales. 1985. Enzymatic profile of Prototheca species. Mycopathologia, 92: 81-82.

Costa E.O., A.R. Ribeiro, P.A. Melville, M.S. Prada, A.C. Carciofi, and E.T. Watanabe. 1996. Bovine mastitis due to algae of the genus Prototheca. Mycopathologia, 137: 85-88.

Costa E.O., P.A. Melville, A.R. Ribeiro, E.T. Watanabe and M.C.F.F. Parolari. 1997. Epidemiologic study of environmental sources in a Prototheca zopfii outbreak of bovine mastitis. Mycopathologia, 137: 33-36.

Cunha L.T., S.M.P. Pugine, M.R.M. Silva, E.J.X. Costa and M.P. Melo. 2010. Microbicidal action of indole-3-acetic acid combined with horseradish peroxidase on Prototheca zopfii from bovine mastitis. Mycopathologia, 169: 99-105.

Cunha L.T., S.P. Pugine, C.R. Valle, A.R. Ribeiro, E.J.X. Costa and M.P. De Melo. 2006. Effect of Prototheca zopfii on neutrophil function from bovine milk. Mycopathologia, 162: 421-426.

Galan F., P.G. Martos, M.J. Palomo, M.Beltran, J.L. Gil and J. Mira. 1997. Onychoprotothecosis due to Prototheca wickerhami. Mycopathologia, 137: 75-77.

Jagielski T., H. Lassa, J. Ahrholdt, E. Malinowski E. and U. Rosler. 2011. Genotyping of bovine Prototheca mastitis isolates from Poland. Vet. Microbiol. 149: 283-287.

Jagielski T., H. Lassa, J. Ahrholdt, U. Rosler and E. Malinowski. 2010. Molecular characterization of Polish Prototheca zopfii mastitis isolates and first isolation of Prototheca blaschkeae in Poland. Pol. J. Vet. Sci. 13: 725-729.

Kirk J. and R. Mellenberger. Mastitis control program for Prototheca mastitis in dairy cows" http://www.uwex.edu/milkquality/ $\mathrm{PDF} /$ prototheca.pdf

Krajewska-Kułak E., C. Łukaszuk, W. Niczyporuk and J. Trybuła. 1998. Evaluation of activity of selected hydrolytic enzymes of the yeast-like fungi of Candida isolated from urether. Mikol. Lek. 5: 165-170 (in Polish)

Lass-Flörl C. and A. Mayr. 2007. Human protothecosis. Clin. Microbiol. Rev. 20: 230-242,.

Lassa H., T. Jagielski and E. Malinowski. 2011. Effect of different heat treatments and disinfectants on the survival of Prototheca zopfii. Mycopathologia, 171: 177-182.

Malinowski E., H. Lassa and A. Kłossowska. 2002. Isolation of Prototheca zopfii from inflamed secretion of udders. Bull. Vet. Inst. Pulawy, 46: 295-299.

Marques S., E. Silva, J. Carvalheira and G. Thompson. 2010. In vitro susceptibility of Prototheca to $\mathrm{pH}$ and salt concentration. Mycopathologia, 169: 297-302,

Marques S., E. Silva, J. Carvalheira and G. Thompson. 2006. In vitro antimicrobial susceptibility of Prototheca wickerhamii and Prototheca zopfii isolated from bovine mastitis. J. Dairy Sci. 89: 4202-4204.

Padhye A.A., J.G. Baker and D.F. D’amato. 1979. Rapid identification of Prototheca species by the API 20C System. J. Clin. Microbiol. 10: $579-582$.

Roesler U., A. Moller, A. Hensel, D. Baumann and U. Truyen. 2006. Diversity within the current algal species Prototheca zopfii: a proposal for two Prototheca zopfii genotypes and description of a novel species, Prototheca blaschkeae sp. nov. Int. J. Syst. Evol. Microbiol. 56: 419-1425. 